\title{
A Virtual Reality Cataract Surgery Course for Residents
}

\author{
Samantha K. Paul, ScB ${ }^{1}$ Ingrid U. Scott, MD, MPH² \\ ${ }^{1}$ Alpert Medical School, Brown University, Providence, Rhode Island \\ ${ }^{2}$ Departments of Ophthalmology and Public Health Sciences, \\ Penn State College of Medicine, Hershey, Pennsylvania \\ ${ }^{3}$ Division of Ophthalmology, Brown University, Alpert Medical \\ School, Providence, Rhode Island \\ ${ }^{4}$ Section of Ophthalmology, Providence Veterans Affairs Medical \\ Center, Providence, Rhode Island
}

\author{
Alfred A. Paul, MD ${ }^{3,4}$ Paul B. Greenberg, MD, MPH 3,4
}

Journal of Academic Ophthalmology 2018;10:e41-e42.

\author{
Address for correspondence Paul B. Greenberg, MD, MPH, Section of \\ Ophthalmology, Providence Veterans Affairs Medical Center, \\ 830 Chalkstone Avenue, Providence, RI 02908-4799 \\ (e-mail: paul_greenberg@brown.edu).
}
Abstract
Keywords
- virtual reality
- cataract surgery
- ophthalmology
residency training

We report on two key updates to the publically available Brown ophthalmology residency virtual reality (VR) cataract surgery course. The first is a validated proficiency-based VR simulator test. The second is a mental skills training curriculum derived from a course shown to decrease novice general surgeons' cognitive stress under difficult performance conditions.
Virtual reality (VR) training for novice ophthalmic surgeons has been shown to improve operating performance and decrease rates of complications associated with cataract surgery. ${ }^{1}$ Mental skills are an important aspect of surgical training and are often taught in VR settings ${ }^{2}$ but have not been well studied in ophthalmology. Herein we present a publically available VR cataract surgery course that integrates mental skills training into its learning objectives.

The course consists of didactics based on the American Academy of Ophthalmology Basic and Clinical Science Course and training modules with the EyeSi surgical simulator (VRmagic, Manheim, Germany). The course also includes administration of a validated VR practical test ${ }^{3}$ at the end of the second year of ophthalmology residency training, which is 3 years in duration in the United States. The test consists of seven EyeSi modules selected for their ability to discriminate between novice and experienced cataract surgeons. We focused on junior trainees to identify those who may need extra attention later in training.

In addition, the VR cataract surgery course has a mental skills component. Mental skills are psychological techniques used by professional athletes, pilots, and military personnel to enhance learning, improve performance, and assist with stress management. Surgeons and surgical trainees have also used mental skills strategies to attain superior operating room performance and lower stress levels. ${ }^{2}$ Strategies include mental imagery, stress management, goal setting, and pre-performance routines. The impact of mental skills is determined by the evaluation of surgical performance on VR simulators, questionnaires that quantify stress and confidence levels, or performance in other simulated clinical scenarios.

The mental skills curriculum in the VR course consists of eight modules from a course shown to decrease novice general surgeons' cognitive stress under difficult performance conditions. ${ }^{4,5}$ Completed by second-year ophthalmology residents, the modules are integrated into VR sessions and cover energy management, goal setting, mental imagery, refocusing strategies, and preoperative mental routines. Residents review one new module with an attending physician before each VR session. To assess the efficacy of the mental skills, residents complete a Test of Performance Strategies (TOPS) questionnaire before the first and after the last mental skills sessions.

We look forward to assessing the impact of this course on resident VR and operating room cataract surgery outcomes and receiving feedback from other ophthalmology residency training programs that may use our course to update their cataract surgery training curricula.

Course link: https://doi.org/10.7301/Z0X065JZ. received

January 19, 2018

accepted

March 6, 2018
DOI https://doi.org/

10.1055/s-0038-1641609. ISSN 2475-4757.
Copyright $\odot 2018$ by Thieme Medical Publishers, Inc., 333 Seventh Avenue, New York, NY 10001, USA. Tel: +1(212) 584-4662.
License terms

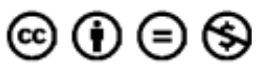




\section{Conflict of Interest}

None declared.

\section{Disclaimer}

The views expressed in this article are those of the authors and do not necessarily reflect the position or policy of the Department of Veterans Affairs or the United States government.

\section{Funding}

This work was supported in part by an educational grant from the Alpert Medical School, Brown University, Providence, Rhode Island, and supported with resources and the use of facilities at the Providence VA Medical Center, Providence, Rhode Island.

\section{References}

1 Thomsen ASS, Bach-Holm D, Kjærbo H, et al. Operating room performance improves after proficiency-based virtual reality cataract surgery training. Ophthalmology 2017;124(04):524-531

2 Anton NE, Bean EA, Hammonds SC, Stefanidis D. Application of mental skills training in surgery: a review of its effectiveness and proposed next steps. J Laparoendosc Adv Surg Tech A 2017;27(05):459-469

3 Thomsen ASS, Kiilgaard JF, Kjaerbo H, la Cour M, Konge L. Simulation-based certification for cataract surgery. Acta Ophthalmol 2015;93(05):416-421

4 Stefanidis D, Anton NE, Howley LD, et al. Effectiveness of a comprehensive mental skills curriculum in enhancing surgical performance: results of a randomized controlled trial. Am J Surg 2017;213(02):318-324

5 Stefanidis D, Anton NE, McRary G, et al. Implementation results of a novel comprehensive mental skills curriculum during simulator training. Am J Surg 2017;213(02):353-361 